
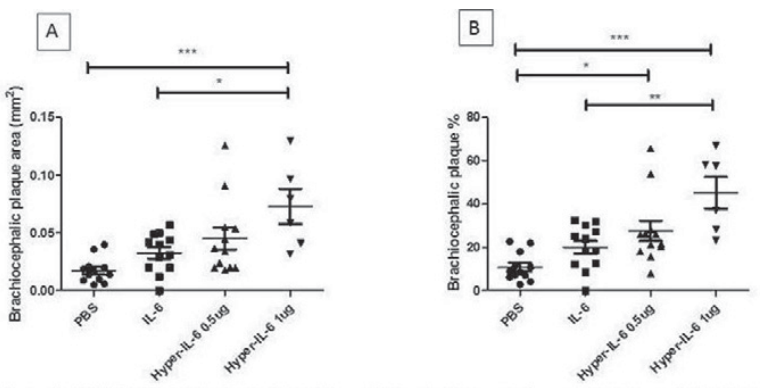

Figure1. (A) Significantly larger brachiocephalic plaque area in $a p o E^{-}$mice administere Hyper-IL-6 1ug compared to mice administered IL-6 or PBS. B) Significantly higher brachiocephalic plaque percentage in $a p o E^{-/}$mice administered Hyper-IL-6 compared to PBS, and significantly higher brachiocephalic plaque percentage in $\mathrm{apoE}^{*}$ mice administered hyperIL-6 $1 \mu \mathrm{g}$ compared to IL-6.

Conclusions: IL-6 trans-signaling leads to accelerated atherosclerosis in disease susceptible animals. This effect is independent of changes in serum lipid profiles. References:

[1] Rose-John S. IL-6 Trans-Signaling via the Soluble IL-6 Receptor: Importance for the Pro-Inflammatory Activities of IL-6. Int. J. Biol. Sci. 2012;8(9):12371247.

Acknowledgements: This work was funded by Arthritis Research UK, grant number 20760.

Disclosure of Interest: None declared

DOI: 10.1136/annrheumdis-2017-eular.2871

\title{
THU0026 OSM IS MORE EFFECTIVE THAN IL-6 AT INDUCING ENDOMT OF HUMAN DERMAL MICROVASCULAR CELLS
}

K. Nevin ${ }^{1}$, L. Stawski ${ }^{2}$, M. Feeney ${ }^{1}$, N. Wisniacki ${ }^{1}$, M. Trojanowska ${ }^{2}$.

${ }^{1}$ Immuno-Inflammation Therapeutic Area Unit, GlaxoSmithKline, Stevenage,

United Kingdom; ${ }^{2}$ Arthritis Centre, Boston University, Boston, United States

Background: Oncostatin-M (OSM) and interleukin-6 (IL-6) are members of the IL-6 superfamily and signal via glycoprotein 130 (gp130). OSM signals with either the type I receptor complex, gp130/ Leukemia Inhibitory Factor Receptor (LIFR), or the type II receptor complex, gp130/OSM receptor (OSMR), whilst IL-6 signals via gp130 with the IL-6 receptor (IL-6R) or by trans signalling with soluble IL-6R (sIL6-R). Endothelial cells (ECs) express both gp130 and OSMR [Brown TJ et al 1991], however it is unclear whether ECs express IL-6R [Romano $M$ et al 1997; Nilsson MB et al 2005]. Endothelial to mesenchymal transition (EndoMT) is the phenotypic transition of ECs into mesenchymal cells where ECs lose their specific EC markers, detach from the endothelial layer and initiate the expression of mesenchymal cell products. EndoMT is associated with vascular dysfunction, one of the early manifestations of systemic sclerosis. The role of OSM and IL-6 in EndoMT has not yet been fully elucidated.

Objectives: To determine the effect of OSM and IL-6/sIL-6R on microvascular EC migration, proliferation and EndoMT.

Methods: Human dermal microvascular ECs (HDMECs) were treated with human recombinant proteins OSM (1-100 ng/mL), IL-6 (10-100 ng/mL) and slL-6R (10-100 $\mathrm{ng} / \mathrm{mL})$. Cell migration and proliferation were measured with Live-Cell imaging system over 50 hours and analysed using a two-way ANOVA. Secretion of Collagen type I protein was measured at 48 hours by western blot analysis of media supernatant from HDMEC cultures. Changes in VE-Cadherin and F-actin expression were examined by immunofluorescence over 72 hours.
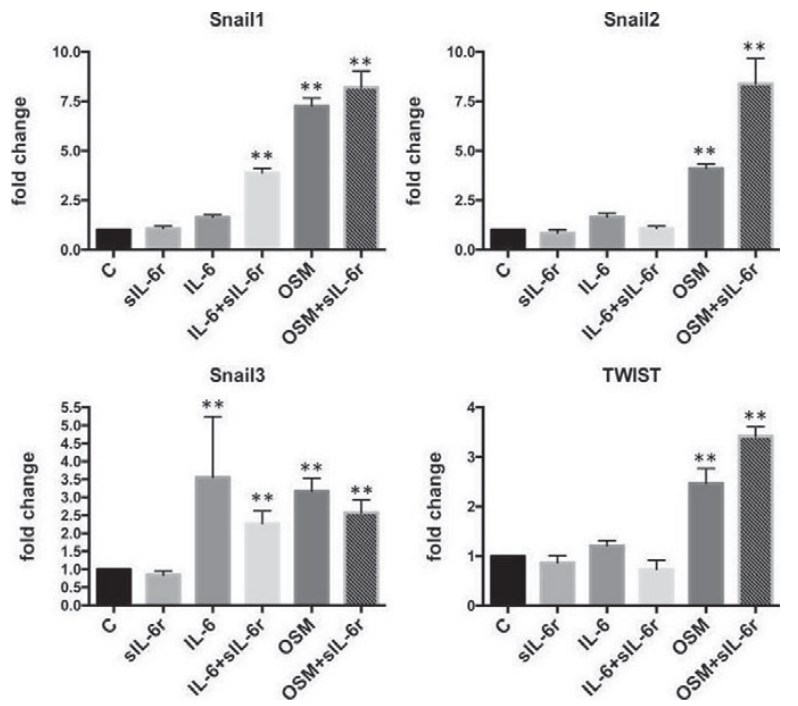

Gene expression was measured at 3 hours using quantitative RT-PCR analysis and analysed by Student's paired T-Test.

Results: OSM and IL-6, with or without IL-6R, significantly increased $(P<0.001$, $\mathrm{n}=3$ donors) HDMEC migration and proliferation and secretion of extracellular matrix (ECM) protein Collagen I compared to the control group. OSM, but not IL-6 with or without SIL-6R, reduced expression of EC marker VE-Cadherin and increased expression of elongated $\mathrm{F}$-actin stress fibres $(\mathrm{n}=2$ donors). OSM significantly affected $(\mathrm{P}<0.05, \mathrm{n}=3$ donors) expression of EndoMT genes SNAIL1, SNAIL2, SNAIL3 and TWIST [Figure 1] and ECM genes MMP1, MMP2 TIMP1 and TIMP2 compared to the control. Many of the gene changes in response to OSM were further augmented by co-stimulation with sIL-6R. IL-6 with or without slL-6R only significantly affected $(\mathrm{P}<0.05, \mathrm{n}=3$ donors) EndoMT genes SNAIL1 and SNAIL3 and ECM gene TIMP1.

Conclusions: OSM induced a stronger EndoMT phenotype in HDMECs in comparison to IL-6, suggesting that OSM is capable of initiating EndoMT activity in microvascular cells. The augmented effects observed for OSM with SIL-6R also suggests that OSM is capable of binding the sIL-6R and initiating signalling in HDMECs in vitro.

References:

[1] Brown TJ, Rowe JM, Liu JW and Shoyab M. Regulation of IL-6 expression by oncostatin M. J Immunol 1991:147:2175-2180.

[2] Nilsson MB, Langley RR and Fidler IJ. Interleukin-6, secreted by human ovarian carcinoma cells, is a potent proangiogenic cytokine. Cancer Res 2005:65:10794-10800.

[3] Romano M, Sironi M, Toniatti C, Polentarutti N, Fruscella P, Ghezzi P, Faggioni R, Luini W, van Hinsbergh V, Sozzani S, Bussolino F, Poli V, Ciliberto G, and Mantovani A. Role of IL-6 and its soluble receptor in induction of chemokines and leukocyte recruitment. Immunity 1997:6:315-325.

Disclosure of Interest: None declared

DOI: 10.1136/annrheumdis-2017-eular.1271

\section{THU0027 CLUSTERIN IS ELEVATED IN SERUM AND MUSCLE TISSUE IN IDIOPATHIC INFLAMMATORY MYOPATHIES AND IS ASSOCIATED WITH DISEASE ACTIVITY}

T. Lennerová, L. Vernerová, M. Klein, M. Tomčík, H. Mann, V. Hrušková,

K. Pavelka, J. Vencovský, L. Šenolt. Institute of Rheumatology and Department of Rheumatology, First Faculty of Medicine, Charles University, Prague, Czech Republic

Background: Clusterin (also known as apolipoprotein $\mathrm{J}$ ) is a molecular chaperone that participates in inflammatory and apoptotic processes. Recent data indicate its possible protective role in the development of chronic autoimmune disorders. Objectives: The aim of this study was to analyse the skeletal muscle expression of clusterin and its serum levels in patients with idiopathic inflammatory myopathies (IIM) and in healthy donors, and to examine the association of clusterin with disease activity.

Methods: Clusterin mRNA expression in skeletal muscle specimens, obtained by muscle biopsy (mini-invasive Bergstrom technique), was determined using qPCR in 10 patients with IIM and 10 healthy subjects. Serum concentrations of clusterin were measured by ELISA (Biovendor) in 65 patients with IIM (27 dermatomyositis (DM), 28 polymyositis (PM), 10 immune-mediated necrotizing myopathy (IMNM)) and in 54 healthy individuals. Disease activity was assessed using myositis intention to treat index (MITAX), myositis disease activity assessment visual analogue scales (MYOACT), health assessment questionnaire (HAQ) and global disease assessment evaluated by doctor and patient. Data are presented as mean \pm SD.

Results: Clusterin mRNA expression in skeletal muscles was increased in patients with IIM compared to healthy donors $(p=0.029)$. In addition, serum clusterin levels were significantly higher in all IIM patients than in healthy subjects $(87.1 \pm 22.8$ vs $68.4 \pm 12.4, p<0.0001)$ and also in individual subsets of patients in comparison to the control group (DM: 87.7 $\pm 24.7, P M: 86.1 \pm 23.2$, IMNM: 88.15 $\pm 18.0, p<0.0001$ for all). Clusterin levels in all patients with IIM positively correlated with MYOACT $(r=0.337, p=0.008), \operatorname{MITAX}(r=0.357, p=0.004)$ and global disease assessment evaluated by doctor $(r=0.309, p=0.015)$. In patients with $D M$, positive correlations with MYOACT $(r=0.499, p=0.009)$, MITAX $(r=0.491, p=0.009), H A Q(r=0.470$, $\mathrm{p}=0.014)$, global disease assessment evaluated by doctor $(r=0.559, p=0.004)$, $\gamma$-glutamyl transpeptidase and asparate aminotransferase were found $(r=0.504$, $p=0.007 ; r=0.429, p=0.025$, respectively). PM and IMNM subsets showed no significant association.

Conclusions: We demonstrate increased local and systemic expression of clusterin in IIM patients compared to healthy individuals and its association with disease activity, especially in dermatomyositis.

Acknowledgements: Supported by the project of MHCR for conceptual development of research organization 00023728 and project NV16-33746A.

Disclosure of Interest: None declared

DOI: 10.1136/annrheumdis-2017-eular.5792 